\title{
NOTES
}

\section{Translating a Classic The Experience of Translating Kanyasulkam}

\section{T . Vijay Kumar \& C Vijayasree}

It is indeed a happy occasion to share our experience of translating Kanyasulkam when the year-long celebrations of the 150th birth anniversary of its author Gurajada Venkata Appa Rao's (1862-1915) are still fresh in memory. Kanyasulkam was first performed in 1892 and published in 1897. The second, 'recast' edition that is currently available was published in 1909. Widely regarded as the "adikavyam" of modern Telugu literature, the play enjoys several distinctions: it was the first social play in Telugu, the first full-length play in prose, the first to employ colloquial Telugu, and the first to use 'local' actors. It was made into a film in 1955 and was as successful on screen as it was on stage, and in print. But for Telugu readers, Kanyasulkam is not an archival documentwords and phrases from the play have now become part of their vocabulary, and characters and their mannerisms have become familiar points of reference.

Kanyasulkam was Gurajada's first work in Telugu, in any genre. Prior to this he had written and published poems in English and had also written a series of songs in praise of the Queen under the title "Victoria Prasasti". Even after the publication of the first edition of Kanyasulkam, Gurajada wrote most of his reviews, prefaces, pamphlets, and parodies in English. In fact, he always wrote his letters, diaries, plot summaries, and notes in English. It is indeed ironical that Kanyasulkam which advocates the use of spoken Telugu as the literary dialect had a "Dedication" and "Preface" written in English. 


\section{Social context}

Gurajada was the official epigraphist (in 1895) to the Maharajah of Vizianagaram, H H Ananda Gajapathi Raju (18501897). Ever since he was first introduced to the Maharaja in 1887, Gurajada enjoyed a close rapport with his patron and shared his progressive outlook. The Maharajah held a special place in the colonial administration of the time, and he used his influence with the government to usher in social reforms, particularly those concerning the amelioration of women. As a member of the Madras Legislative Council he proposed the Kanyasulkam Bill-"a Bill to discontinue the sordid practice of selling girls in marriages among the Brahmins under the guise of religion." But the colonial government showed extreme caution in effecting any change in matters concerning familial and religious issues, partly because it was unwilling to incur popular displeasure by seeming to interfere in the "private" matters of the natives, and partly because it suited them to let the status quo remain and allow obsolete social systems to turn into ossified structures. Ananda Gajapathi's Bill was referred to a council of experts and was promptly dropped.

The Maharajah, however, did not lose heart when his efforts failed at the political level-he successfully consolidated public opinion in favour of his cause. Gurajada wrote Kanyasulkam to further his patron's movement for social reform and dedicated the play to him. "... when the question was engaging your Highness's attention," writes Gurajada in his dedication, "an humble servant made a feeble effort to arouse public opinion on the subject, by exposing the evil in a popular drama."

However, though written with express intent "to advance the cause of social reform and to combat a popular prejudice that the Telugu language was unsuited to the stage" ("Preface to the Second Edition" [1909]), the play is far from propagandist. In fact, it displays a healthy scepticism towards idealistic reform movements, and their well-meaning but naïve leaders. The plot revolves around a clever courtesan, a lovable rogue, a young 
widow, an old man who wants to buy as his wife a very young girl and so on-altogether 38 major and minor characters.

\section{How it all began}

The long and arduous process of translating Kanyasulkam began sometime in 2000-2001 when the well-known literary critic Prof Meenakshi Mukherjee was asked by The Hindu to plan and guest-edit a monthly column in their Sunday Literary Review. Titled "Past Continuous", the column published English translation of short extracts from texts in the Indian languages belonging to the early modern period. The largely 19th and early 20th century texts were selected for the continued relevance of the issues they dealt with. As Prof. Mukherjee had made Hyderabad her home after retiring from Jawaharlal Nehru University, Delhi, she wanted to begin the series with a text in Telugu and asked us to help in identifying one. We then suggested Kanyasulkam and as no English translation was easily available, we offered to translate a thousand-word excerpt from it. After its publication, several nonTelugu readers, friends and colleagues wanted to read more of the play. But to everyone's surprise, including ours, it was found that an English translation of the play in its entirety simply did not exist! So, the obvious suggestion everyone made was 'Having made a beginning, why don't you go ahead and complete the task? At least then it will become available to not only non-Telugus but also those Telugus who can't read the original in Telugu'.

Meanwhile, The Book Review Literary Trust, New Delhi was celebrating the silver jubilee of their journal, The Book Review and wanted to venture into publishing books. They were enthused by the response that the extracts published in "Past Continuous" were getting and planned to publish some of these works in full. So, it was only then, with the encouragement provided by readers, critics, and the publisher that we embarked on the daunting task of translating Kanyasulkam. 
From the very beginning, we knew that we were trying to translate the untranslatable. But our attempt was an act of homage to one of the greatest classics of modern Indian literature, and we are happy that our endeavour has been recognized as such. When His Excellency the President of India Sri KR Narayanan released the translation in the Rashtrapathi Bhavan (in July 2002), or when Sri Ashoka Gajapathi Raju, Revenue Minister and the great grandson of Sri Ananda Gajapathi Raju (1850-1897), the Maharajah of Vizianagaram and Gurajada's patron, agreed to launch the book in Hyderabad (in Sep 2002), or when the play came to be included in the syllabuses of universities in India and abroad-on all such happy and proud occasions, we were acutely aware that the honour belongs entirely to the original. The translation, in a way, was merely a pretext to recall and celebrate the original text.

\section{Basic issues in this translation}

Before and during the course of translating Kanyasulkam, we discussed and agreed upon certain issues that will have a bearing on our method of translation. The first question we asked ourselves was 'Who is the target reader of this translation?' From the very beginning we were clear that our translation was meant for an Indian reader who wants to but cannot read the original in Telugu. This imagined Indian reader may not be familiar with some of the specific customs, traditions, and cultural practices depicted in the book but perhaps can recognize the similarities or find equivalents in her/his own linguistic and cultural milieu. Retaining the title as 'Kanyasulkam' without giving into the temptation of changing it to 'Bride-Price' or even adding an explanatory subtitle was a conscious decision as we had the implicit faith that a reader familiar with Indian social, cultural, and linguistic milieu would know the meaning of the word or will be able to make an intelligent guess.

The second issue that we had to resolve was 'What kind of translation?'We agreed that we should not iron out all the cultural or textual characteristics and produce a 'smooth' translation. 
Readability in the target language and fidelity to the original were our guiding principles and we did not want to sacrifice one for the sake of the other. In this regard, we were cautious not to make the same mistake (at least in our opinion) that an earlier translation made by totally anglicizing the text. We wanted to make it clear, implicitly, that ours is a translation of an Indian, Telugu text.

'How much liberty should we allow ourselves to take with the original?' was the next issue that presented itself during the course of the translation. We were aware that several Indian language texts undergo dramatic transformation in the hands of translators who feel free to revise, update, edit, or improve the original exercising their own judgment. We, however, restricted ourselves to the task of translation and did not add or delete anything to or from the original to make it either politically correct or ideologically compliant.

\section{The translation process}

The process of translating Kanyasulkam was, not unexpectedly, strenuous and highly demanding. Besides the familiar problems that most non-English texts pose while being translated into English-problems such as kinship terms, culture specific vocabulary, dialects etc-Kanyasulkam presents certain additional complications. One such problem was the proliferation of English words, phrases, idioms etc in the text. These words stand out in the original and serve to define the character of Girisam. But how does one carry that aspect into the translation where the rest of the text too is in English? We used special typographical markers to highlight the English words in the original. Similarly, certain English words appear in their Telugized form ('kumphini'for company, 'konstibu' for constable etc) and several Urdu words are also used (particularly the vocabulary of revenue administration). We had to make a judicious choice between translating them into 'standard' English and retaining some of them as in the original to indicate the linguistic richness of the text. 
We did not try to give any 'period flavor' to the English used in the translation to represent the time of the original. We used the English that is used in the contemporary Indian (formal) context. We were also familiar with the practice among some Indian translators of using dialects of English (cockney, pidgin etc) to reflect the dialects of the 'standard' language used in the original. We considered the option but finally decided against it as we felt that the dialects of English that are available to us are culture specific and therefore cannot be treated as free floating models. Sometimes, however, we did coin words to convey the humour succinctly-one such coinage which has been widely appreciated is "broomance" (broom + romance) for "cheepuru katta sringaaram".

One of the characteristics of Telugu speech, as it is of speech in many Indian languages, is the use of echo words (such as "marbles-geerbles") in which the second part is merely alliterative and entirely nonsensical. We retained a few such constructions to indicate this linguistic feature.

\section{Unfinished tasks}

Unlike many texts which lose general readers when they are labelled as 'classics', Kanyasulkam continues to have popular appeal and is considered 'an all-time best-seller'. Several publishers still bring out new editions and reprints. But in spite of, or perhaps because of, the many editions in circulation, we found to our dismay, that there isn't a single definitive edition of this seminal text. As we were wrestling with the text, and more so with the textual variations among the different editions, we fondly desired a definitive and fully annotated edition of the original that can then become the basis for an authentic translation. We also dreamed of the day when we could muster enough courage to attempt this impossible task and bring out an edition which will bear resemblance to the Variorum Editions of Shakespeare's plays. 
By and large, the translation has been well received by the readers and fellow practitioners. However, we realized that a few inaccuracies and some typos had crept into it either due to oversight or due to lack of time to copy edit the text. We also noticed that there is still a lot of scope to annotate the plethora of references in the text. We started making notes and hoped to bring out a new, paperback edition of the translation that is error free and will provide the reader with more information and generally make the overall experience of reading the classic even richer.

While this latter task may still be accomplished, the earlier dream - of bringing out a definitive edition in Telugu-will now have to be realized by someone else who has the resources, the stamina and the courage to undertake the task. Best wishes to that brave soul.

(*I have used 'we' and 'our' in this essay because though Prof C Vijayasree [1953-2012] is no more, the experiences shared here belong to both of us. I am confident that she would have approved-as she always did-the manner in which I have presented them. I offer this essay as a tribute to her. TVijay Kumar)

(A shorter version of this essay was presented in the session "Meet the Translator" at the Workshop on "Translation and Media" organized by Department of English and Department of Mass Communication \& Journalism, Manonmaniam Sundaranar University, Tirunelveli in collaboration with National Translation Mission, Mysore. 19-21 February 2013). 